\title{
Suzuki-Edelstein Type Contractions via Auxiliary Functions
}

\author{
Peyman Salimi $^{1}$ and Erdal Karapınar ${ }^{2}$ \\ ${ }^{1}$ Department of Mathematics, Astara Branch, Islamic Azad University, Astara, Iran \\ ${ }^{2}$ Department of Mathematics, Atilim University, Incek, 06836 Ankara, Turkey
}

Correspondence should be addressed to Erdal Karapınar; erdalkarapinar@yahoo.com

Received 6 November 2012; Revised 7 January 2013; Accepted 25 February 2013

Academic Editor: Andrzej Swierniak

Copyright (c) 2013 P. Salimi and E. Karapınar. This is an open access article distributed under the Creative Commons Attribution License, which permits unrestricted use, distribution, and reproduction in any medium, provided the original work is properly cited.

We prove the existence and uniqueness of a fixed point of certain type mapping, extension of Suzuki-Edelstein mapping, in a partially ordered complete metric space. Our results extend, improve, and generalize the existence results on the topic in the literature. We state some examples to illustrate our results.

\section{Introduction}

Fixed point theory lies in the center of nonlinear functional analysis because it has a broad range of applications in fields such as economics, computer science, and many others (see, e.g., [1-7]). In particular, fixed point theory is quite useful in finding the solutions of inverse problems and structural optimizations in science and engineering [8-10]. Banach contraction mapping principle [11] is considered to be the fundamental result in this theory. It states that each contraction defined on a complete metric space has a unique fixed point. The strength of Banach's result in applications comes from two remarkable implications of this principle. The first one is that it guarantees the existence and uniqueness of a fixed point of a contraction. The second and most effective one is that it provides a technique to evaluate the fixed point. The importance of these two properties of Banach contraction mapping principle evidently has attracted many prominent mathematicians (see, e.g., [12-16]) interested in the fixed point theory and its applications as the use of this principle has widened considerably since its first appearance [17-21]. In particular, in this paper, we will focus on one of the most remarkable generalizations of Banach contraction mapping principle developed by Edelstein [22]. This theorem can be stated as follows.

Theorem 1. Let $(X, d)$ be a compact metric space and let $T$ be a mapping on $X$. Assume $d(T x, T y)<d(x, y)$ for all $x, y \in X$ with $x \neq y$. Then $T$ has a unique fixed point.
Inspired by Edelstein's theorem, Suzuki [23, 24] further improved Banach's principle through the two theorems below.

Theorem 2. Define a nonincreasing function $\theta$ from $[0,1)$ onto $(1 / 2,1]$ by

$$
\theta(r)= \begin{cases}1 & \text { if } 0 \leq r \leq \frac{(\sqrt{5}-1)}{2}, \\ (1-r) r^{-2} & \text { if } \frac{(\sqrt{5}-1)}{2} \leq r \leq \frac{\sqrt{2}}{2}, \\ (1+r)^{-1} & \text { if } \frac{\sqrt{2}}{2} \leq r<1 .\end{cases}
$$

Then for a metric space $(X, d)$, the following is equivalent.

(1) $X$ is complete.

(2) Every mapping $T$ on $X$ satisfying the following has a fixed point: there exists $r \in[0,1)$ such that $\theta(r) d(x, T x) \leq d(x, y)$ implies $d(T x, T y) \leq r d(x, y)$ for all $x, y \in X$.

Theorem 3. Let $(X, d)$ be a compact metric space and let $T$ be a mapping on $X$. Assume that $(1 / 2) d(x, T x)<d(x, y)$ implies $d(T x, T y)<d(x, y)$ for all $x, y \in X$. Then $T$ has a unique fixed point.

Theorems 2 and 3 are extensively studied by many authors (see, e.g., [25-29]). It is worth to point out that the 
studies mentioned above can be classified as the extensions of Banach's principle on compact/complete metric spaces, which are totally ordered.

On the other hand, Turinici [30], Ran and Reurings [31], and Nieto and Rodríguez-López [32] proved an analog of the desired Banach's principle in the context of partially ordered complete metric spaces for a certain class of maps. In particular, Ran and Reurings [31] applied their result to solve a matrix equation and Nieto and Rodríguez-López [32] applied their theorem to guarantee the existence and uniqueness of the solution of some boundary value problems.

Motivated by all these developments, we shall prove new fixed point theorems extending Edelstein-Suzuki type contraction results in the setting of partially ordered complete metric spaces.

\section{Main Results}

We denote by $\Phi_{\varphi}$ the set of functions $\varphi:[0,+\infty) \rightarrow[0,+\infty)$ satisfying the following condition:

$$
(\theta 1) \varphi(t) \leq \frac{1}{2} t \quad \forall t \geq 0 .
$$

We denote by $\Phi$ the set of nondecreasing functions $\phi$ : $[0,+\infty) \rightarrow[0,+\infty)$ such that

$$
\lim _{n \rightarrow+\infty} \phi^{n}(t)=0 \forall t>0 .
$$

We have the following lemma.

Lemma 4 (see $[33,34])$. If $\psi \in \Phi$, then $\phi(t)<t$ for all $t>0$.

Definition 5 (see [35]). Let $f: X \rightarrow X$ and $\alpha: X \rightarrow \mathbb{R}^{+}$. We say that $f$ is $\alpha$-admissible if

$$
x, y \in X \alpha(x, y) \geq 1 \Longrightarrow \alpha(f x, f y) \geq 1
$$

Theorem 6. Let $(X, d, \preceq)$ be an ordered metric space such that $(X, d)$ is complete. Let $f: X \rightarrow X$ be a self-mapping. Assume that there exists $\varphi \in \Phi_{\varphi}$ such that

$$
\begin{aligned}
& \varphi(d(x, f x)) \leq \alpha(x, y) d(x, y) \text { implies } \\
& \alpha(x, y) d(f x, f y) \leq \phi(d(x, y))
\end{aligned}
$$

for all comparable $x, y \in X$, where $\phi \in \Phi$. If the following conditions hold:

(i) $f$ is non-decreasing, continuous, and $\alpha$-admissible,

(ii) there exists $x_{0} \in X$ such that $x_{0} \preceq f x_{0}$ and $\alpha\left(x_{0}, f x_{0}\right) \geq 1$,

then $f$ has a fixed point in $X$.

Proof. Let $x_{0} \preceq f x_{0}$. If $x_{0}=f x_{0}$, then the theorem follows. Hence we suppose that $x_{0} \prec f x_{0}$. Define a sequence $\left\{x_{n}\right\}$ by $x_{n}=f^{n} x_{0}=f x_{n-1}$ for all $n \in \mathbb{N}$. Since $f$ is non-decreasing and $x_{0} \prec f x_{0}$ then

$$
x_{0} \prec x_{1} \preceq x_{2} \preceq \cdots,
$$

and hence $\left\{x_{n}\right\}$ is an increasing sequence. If $x_{n}=x_{n+1}=f x_{n}$ for some $n \in \mathbb{N}$, then the result is proved as $x_{n}$ is a fixed point of $f$. In what follows, we will suppose that $x_{n} \neq x_{n+1}$. Hence, $\left\{x_{n}\right\}$ is a strictly increasing sequence. Since $f$ is $\alpha$-admissible and there exists $x_{0} \in X$ such that $\alpha\left(x_{0}, f x_{0}\right) \geq 1$, we find $\alpha\left(x_{1}, x_{2}\right)=\alpha\left(f x_{0}, f x_{1}\right) \geq 1$. By continuing this process, we get $\alpha\left(x_{n}, x_{n+1}\right) \geq 1$ for all $n \in \mathbb{N} \cup\{0\}$. Now we obtain that

$$
\begin{aligned}
\varphi\left(d\left(x_{n-1}, f x_{n-1}\right)\right) & \leq \frac{1}{2} d\left(x_{n-1}, f x_{n-1}\right) \\
& \leq d\left(x_{n-1}, f x_{n-1}\right) \\
& \leq \alpha\left(x_{n-1}, f x_{n-1}\right) d\left(x_{n-1}, f x_{n-1}\right)
\end{aligned}
$$

and $x_{n-1}$ and $f x_{n-1}$ are comparable for all $n \in \mathbb{N}$. Then by (5), we have

$$
\alpha\left(x_{n-1}, f x_{n-1}\right) d\left(f x_{n-1}, f^{2} x_{n-1}\right) \leq \phi\left(d\left(x_{n-1}, f x_{n-1}\right)\right) .
$$

Then

$$
\begin{aligned}
d\left(x_{n}, x_{n+1}\right) & \leq \alpha\left(x_{n-1}, x_{n}\right) d\left(x_{n}, x_{n+1}\right) \\
& \leq \phi\left(d\left(x_{n-1}, x_{n}\right)\right)
\end{aligned}
$$

By induction, we have

$$
d\left(x_{n}, x_{n+1}\right) \leq \phi^{n}\left(d\left(x_{0}, x_{1}\right)\right) .
$$

By taking the limit as $n \rightarrow+\infty$ in the inequality above, we deduce

$$
\lim _{n \rightarrow+\infty} d\left(x_{n}, x_{n+1}\right)=0 \text {. }
$$

For a fixed $\epsilon>0$, there exists $N \in \mathbb{N}$ such that

$$
d\left(x_{n}, x_{n+1}\right)<\epsilon-\phi(\epsilon) \quad \forall n \in \mathbb{N} .
$$

As $\phi$ is nondecreasing, we get

$$
\phi\left(d\left(x_{n}, x_{n+1}\right)\right) \leq \phi(\epsilon-\phi(\epsilon)) \leq \phi(\epsilon) \quad \forall n \in \mathbb{N} .
$$

Then

$$
\begin{aligned}
d\left(x_{n}, x_{n+2}\right) & \leq d\left(x_{n}, x_{n+1}\right)+d\left(x_{n+1}, x_{n+2}\right) \\
& <\epsilon-\phi(\epsilon)+\phi\left(d\left(x_{n}, x_{n+1}\right)\right) \\
& \leq \epsilon-\phi(\epsilon)+\phi(\epsilon)=\epsilon .
\end{aligned}
$$

By continuing this process, we get

$$
d\left(x_{n}, x_{n+k}\right)<\epsilon
$$

for all $n \geq N$ and $k \in \mathbb{N}$. Consequently $\lim _{m, n, \rightarrow+\infty}$ $d\left(x_{n}, x_{m}\right)=0$. Hence $\left\{x_{n}\right\}$ is a Cauchy sequence. Since $X$ is complete, there is $z \in X$ such that $x_{n} \rightarrow z$. Now, since $f$ is continuous, we have

$$
f z=\lim _{n \rightarrow \infty} f x_{n}=\lim _{n \rightarrow \infty} x_{n}=z .
$$

So $z$ is a fixed point of $f$. 
Example 7. Let $X=[0, \infty)$. Define the metric $d$ on $X$ by $d(x, y)=|x-y|$. Define $f: X \rightarrow X$ by

$$
f(x)= \begin{cases}\frac{1}{2} x-\frac{1}{4} x^{2}, & \text { if } x \in[0,1], \\ \ln x+\frac{1}{2} & \text { if } x \in(1, \infty)\end{cases}
$$

and $\alpha: X^{2} \rightarrow \mathbb{R}^{+}$by

$$
\alpha(x, y)= \begin{cases}1, & \text { if } x, y \in[0,1] \\ 0 & \text { otherwise }\end{cases}
$$

Let $\psi(t)=(1 / 2) t$. Let $x \preceq y$ if and only if $x \leq y$. Hence the conditions of Theorem 6 hold; that is, $f$ has a fixed point.

Proof. Let $x, y \in X$. First we assume that $\alpha(x, y) \geq 1$. Then $x, y \in[0,1]$. On the other hand, for all $x, y \in[0,1]$, we have $f x \leq 1 / 2$. Hence $\alpha(f x, f y) \geq 1$. That is, $f$ is $\alpha$-admissible. Clearly, $\alpha(0, f 0) \geq 1$ and $0 \preceq f 0$. Let $x \geq y$, and $x, y \in[0,1)$. Then we derive

$$
\begin{aligned}
\alpha(x, y) d(f x, f y) & =\frac{x-y}{2}-\left(\frac{x^{2}-y^{2}}{4}\right) \\
& \leq \frac{x-y}{2}=\psi(d(x, y)) .
\end{aligned}
$$

Next we assume that $\alpha(x, y)=0$. As a result we find

$$
0=\alpha(x, y) d(f x, f y) \leq \psi(d(x, y))
$$

Then the conditions of Theorem 6 hold; therefore, $f$ has a fixed point.

Theorem 8. Let $(X, d, \preceq)$ be an ordered metric space such that $(X, d)$ is complete. Let $f: X \rightarrow X$ be a self-mapping. Assume that there exists $\varphi \in \Phi_{\varphi}$ such that

$$
\begin{aligned}
& \varphi(d(x, f x)) \leq \alpha(x, y) d(x, y) \text { implies } \\
& \alpha(x, y) d(f x, f y) \leq \phi(d(x, y))
\end{aligned}
$$

for all comparable $x, y \in X$, where $\phi \in \Phi$. If the following conditions hold:

(i) $f$ is non-decreasing and $\alpha$-admissible,

(ii) there exists $x_{0} \in X$ such that $x_{0} \preceq f x_{0}$ and $\alpha\left(x_{0}, f x_{0}\right) \geq 1$,

(iii) for a strictly increasing sequence $\left\{x_{n}\right\} \subset X$, converging to $x \in X$ one has $x_{n} \prec x$ for all $n \in \mathbb{N}$,

(iv) if $\left\{x_{n}\right\}$ is a sequence in $X$ such that $\alpha\left(x_{n}, x_{n+1}\right) \geq 1$ for all $n$ and $x_{n} \rightarrow x$ as $n \rightarrow \infty$, then $\alpha\left(x_{n}, x\right) \geq 1$ for all $n$,

then $f$ has a fixed point.

Proof. Proceeding as in the proof of Theorem 6, we know that there is a point $z \in X$ such that $x_{n} \rightarrow z$ and $x_{n} \prec z$ by condition (iii). We prove that $z=f z$. From (iv), we have $\alpha\left(x_{n}, z\right) \geq 1$ for all $n \in \mathbb{N}$. Now, we suppose that the following inequalities hold

$$
\begin{aligned}
\frac{1}{2} d\left(x_{n}, x_{n+1}\right) & \geq \varphi\left(d\left(x_{n}, x_{n+1}\right)\right) \\
& >\alpha\left(x_{n}, z\right) d\left(x_{n}, z\right) \geq d\left(x_{n}, z\right), \\
\frac{1}{2} d\left(x_{n+1}, x_{n+2}\right) & \geq \varphi\left(d\left(x_{n+1}, x_{n+2}\right)\right) \\
& >\alpha\left(x_{n+1}, z\right) d\left(x_{n+1}, z\right) \geq d\left(x_{n+1}, z\right)
\end{aligned}
$$

for some $n \in \mathbb{N}$.

Since, $x_{n} \neq x_{n+1}$ for all $n$, we get $d\left(x_{n}, x_{n+1}\right)>0$ for all $n$. Now by Lemma 4 and (9), we have $d\left(x_{n+1}, x_{n+2}\right)<$ $d\left(x_{n}, x_{n+1}\right)$. As a result, we obtain

$$
\begin{aligned}
d\left(x_{n}, x_{n+1}\right) & \leq d\left(x_{n}, z\right)+d\left(x_{n+1}, z\right) \\
& <\frac{1}{2} d\left(x_{n}, x_{n+1}\right)+\frac{1}{2} d\left(x_{n+1}, x_{n+2}\right) \\
& <\frac{1}{2} d\left(x_{n}, x_{n+1}\right)+\frac{1}{2} d\left(x_{n}, x_{n+1}\right)=d\left(x_{n}, x_{n+1}\right)
\end{aligned}
$$

This is a contradiction. Thus, for all $n \in \mathbb{N}$, either

$$
\varphi\left(d\left(x_{n}, x_{n+1}\right)\right) \leq \alpha\left(x_{n}, z\right) d\left(x_{n}, z\right)
$$

or

$$
\varphi\left(d\left(x_{n+1}, x_{n+2}\right)\right) \leq \alpha\left(x_{n+1}, z\right) d\left(x_{n+1}, z\right)
$$

holds. By (21), we have

$$
d\left(f x_{n}, f z\right) \leq \alpha\left(x_{n}, z\right) d\left(f x_{n}, f z\right) \leq \phi\left(d\left(x_{n}, z\right)\right)
$$

or

$$
d\left(f x_{n+1}, f z\right) \leq \alpha\left(x_{n+1}, z\right) d\left(f x_{n+1}, f z\right) \leq \phi\left(d\left(x_{n+1}, z\right)\right) .
$$
is,

Now since $x_{n} \prec z$, we have $d\left(x_{n}, z\right)>0$ for all $n \in \mathbb{N}$, that

$$
d\left(x_{n+1}, f z\right)<d\left(x_{n}, z\right) \text { or } d\left(x_{n+2}, f z\right)<d\left(x_{n+1}, z\right) .
$$

Consequently, there exists an infinite subset $J \subset \mathbb{N}$ such that one of these inequalities holds for every $n \in J$. If we take the limit as $n \rightarrow+\infty$ and $n \in J$, then we get $d(z, f z)=0$, that is, $z=f z$, which is a contradiction. Hence it is absurd to suppose $z \neq f z$. So $z$ is a fixed point of $f$.

Example 9. Let $X=[0, \infty)$. Define the metric $d$ on $X$ by $d(x, y)=|x-y|$. Define $f: X \rightarrow X$ by

$$
f(x)= \begin{cases}\frac{1}{8} x^{2}, & \text { if } x \in[0,1] \\ 4 & \text { if } x=3 \\ x+1 & \text { if } x \in \mathbb{R}^{+} \backslash[0,1] \cup\{3\}\end{cases}
$$


and $\alpha: X^{2} \rightarrow \mathbb{R}^{+}$by

$$
\alpha(x, y)= \begin{cases}1, & \text { if } x, y \in[0,1] \\ \frac{1}{4}, & \text { if } x=3, y=1 \\ 0, & \text { otherwise. }\end{cases}
$$

Let $\varphi(t)=(1 / 2) t$, and $\phi(t)=(1 / 4) t$. Let $x \preceq y$ if and only if $x \leq y$. Hence the conditions of Theorem 8 hold. That is, $f$ has a fixed point.

Proof. Let $x, y \in X$. If $\alpha(x, y) \geq 1$, then $x, y \in[0,1]$. On the other hand, for all $x, y \in[0,1]$, we derive $f x \leq 1 / 2$. Hence $\alpha(f x, f y) \geq 1$. That is, $f$ is $\alpha$-admissible.

Clearly, there exists $x_{0} \in[0,1]$ such that $\alpha\left(x_{0}, f x_{0}\right) \geq 1$.

If $\left\{x_{n}\right\}$ is a sequence in $X$ such that $\alpha\left(x_{n}, x_{n+1}\right) \geq 1$ for all $n$ and $x_{n} \rightarrow x$ as $n \rightarrow \infty$. Then $\left\{x_{n}\right\} \subseteq[0,1]$ and $x \in$ $[0,1]$. That is, $\alpha\left(x_{n}, x\right) \geq 1$ for all $n$. We need to consider the following cases.

(i) If $x, y \in[0,1]$ and $x \geq y$ then

$$
\begin{aligned}
\alpha(x, y) d(f x, f y) & =(f x-f y) \\
& =\frac{1}{8}\left(x^{2}-y^{2}\right) \leq \frac{1}{4}(x-y) .
\end{aligned}
$$

(ii) If $x=3$ and $y=1$, then

$$
\begin{aligned}
\alpha(3,1) d(f 3, f 1) & =\alpha(3,1)(f 3-f 1) \\
& =\frac{31}{32}>\frac{1}{2}=\frac{1}{4}|3-1|=\phi(d(2,3)) .
\end{aligned}
$$

But we see that

$$
\begin{aligned}
\varphi(d(x, f x)) & =\frac{1}{2}|3-f 3|=1>\frac{1}{2} \\
& =\alpha(3,1)|3-1|=\alpha(3,1) d(3,1) .
\end{aligned}
$$

If it is the case that $\alpha(x, y)=0$, then $\alpha(x, y) d(f x, f y)=$ $0 \leq \phi(d(x, y))$. Hence,

$$
\begin{gathered}
\varphi(d(x, f x)) \leq \alpha(x, y) d(x, y) \text { implies } \\
\alpha(x, y) d(f x, f y) \leq \phi(d(x, y)) .
\end{gathered}
$$

Then the conditions of Theorem 8 hold. Consequently, $f$ has a fixed point.

The following notions will be used to show the uniqueness of a fixed point.

(A) For all $x, y \in X$ that are not comparable, there exists $v \in X$ comparable with $x$ and $y$ such that $\alpha(x, v) \geq 1$ and $\alpha(y, v) \geq 1$.

(B) For all $x, y \in X$ that are comparable, there exists $w \in$ $X$ such that $\alpha(x, v) \geq 1$ and $\alpha(y, v) \geq 1$.
Theorem 10. Adding conditions $(A)$ and $(B)$ to the hypotheses of Theorem 8 one obtains uniqueness of the fixed point of $f$.

Proof. Suppose that $z$ and $z^{*}$ are two fixed points of $f$ such that $z \neq z^{*}$. If $z$ and $z^{*}$ are not comparable, by condition (A), there exists $v \in X$ comparable with $z$ and $z^{*}$, such that $\alpha(z, v) \geq 1$ and $\alpha\left(z^{*}, v\right) \geq 1$. Since $f$ is $\alpha$-admissible, we have $\alpha\left(f^{n} z, f^{n} v\right) \geq 1$ and $\alpha\left(f^{n} z^{*}, f^{n} v\right) \geq 1$. Since we have

$$
\begin{aligned}
\varphi\left(d\left(f^{n-1} z, f^{n} z\right)\right) & \leq \frac{1}{2} d\left(f^{n-1} z, f^{n-1} v\right) \\
& \leq d\left(f^{n-1} z, f^{n-1} v\right) \\
& \leq \alpha\left(f^{n-1} z, f^{n-1} v\right) d\left(f^{n-1} z, f^{n-1} v\right)
\end{aligned}
$$

and $f^{n-1} z$ and $f^{n-1} v$ are comparable, by (21), we derive

$$
\begin{aligned}
d\left(f^{n} z, f^{n} v\right) & \leq \alpha\left(f^{n-1} z, f^{n-1} v\right) d\left(f^{n} z, f^{n} v\right) \\
& \leq \phi\left(d\left(f^{n-1} z, f^{n-1} v\right)\right) .
\end{aligned}
$$

By induction, we get

$$
d\left(f^{n} z, f^{n} v\right) \leq \phi^{n}(d(z, v)) .
$$

If $d(z, v)=0$, then $z=v$. That is, $z$ and $z^{*}$ are comparable, which is a contradiction. Hence we suppose that $d(z, v)>0$.

Taking the lim as $k \rightarrow+\infty$ in the first of the inequalities above, we have

$$
\lim _{n \rightarrow+\infty} d\left(f^{n} z, f^{n} x\right)=0 .
$$

Similarly, we obtain that

$$
\lim _{n \rightarrow+\infty} d\left(f^{n} z^{*}, f^{n} v\right)=0 .
$$

From the inequality

$$
\begin{aligned}
d\left(z, z^{*}\right)= & d\left(f^{n} z, f^{n} z^{*}\right) \leq d\left(f^{n} z, f^{n} v\right) \\
& +d\left(f^{n} v, f^{n} z^{*}\right),
\end{aligned}
$$

we get $d\left(z, z^{*}\right)=0$ by taking the limit as $n \rightarrow+\infty$, that is, $z=z^{*}$.

Similarly, if $z$ and $z^{*}$ are comparable, then from (21) and condition (B), it follows that $z=z^{*}$.

We denote by $\Theta_{\gamma}$ the set of functions $\gamma:[0,+\infty) \rightarrow$ $[0,+\infty)$ satisfying the following condition:

$$
(\theta 2) \gamma(t) \geq t \quad \forall t \geq 0
$$

Theorem 11. Let $(X, d, \preceq)$ be an ordered metric space such that $(X, d)$ is complete. Let $f: X \rightarrow X$ be a self-mapping. Assume that there exist $\varphi \in \Phi_{\varphi}$ and $\gamma \in \Theta_{\gamma}$ such that

$$
\begin{gathered}
\varphi(d(x, f x)) \leq \gamma(d(x, y)) \text { implies } \\
\psi(d(f x, f y)) \leq \psi(d(x, y))-\phi(d(x, y))
\end{gathered}
$$

for all comparable $x, y \in X$, where $\phi \in \Phi$ and $\psi \in \Psi$. If the following conditions hold: 
(i) $f$ is non-decreasing,

(ii) there exists $x_{0} \in X$ such that $x_{0} \preceq f x_{0}$,

(iii) if a non-decreasing sequence $\left\{x_{n}\right\}$ is such that $x_{n} \rightarrow x$ as $n \rightarrow \infty$, then

$$
x_{n} \preceq x \quad \forall n \in \mathbb{N},
$$

then $f$ has a fixed point. Moreover, $f$ has a unique fixed point if:

(iv) for all $x, y \in X$ that are not comparable there exists $v \in X$ comparable with $x$ and $y$.

Proof. Let $x_{0} \preceq f x_{0}$. If $x_{0}=f x_{0}$, then the conclusion follows. Hence we suppose that $x_{0} \prec f x_{0}$. Define a sequence $\left\{x_{n}\right\}$ by $x_{n}=f^{n} x_{0}=f x_{n-1}$ for all $n \in \mathbb{N}$. Since $f$ is non-decreasing and $x_{0} \prec f x_{0}$, we have

$$
x_{0} \prec x_{1} \preceq x_{2} \preceq \cdots .
$$

Hence $\left\{x_{n}\right\}$ is a non-decreasing sequence. Since

$$
\begin{aligned}
\varphi\left(d\left(x_{n-1}, f x_{n-1}\right)\right) & \leq \frac{1}{2} d\left(x_{n-1}, f x_{n-1}\right) \\
& \leq d\left(x_{n-1}, f x_{n-1}\right) \leq \gamma\left(d\left(x_{n-1}, f x_{n-1}\right)\right)
\end{aligned}
$$

and $x_{n-1}$ and $f x_{n-1}$ are comparable for all $n \in \mathbb{N}$, by (42), we have

$$
\begin{aligned}
& \psi\left(d\left(f x_{n-1}, f^{2} x_{n-1}\right)\right) \\
& \quad \leq \psi\left(d\left(x_{n-1}, f x_{n-1}\right)\right)-\phi\left(d\left(x_{n-1}, f x_{n-1}\right)\right) \\
& \quad \leq \psi\left(d\left(x_{n-1}, f x_{n-1}\right)\right) .
\end{aligned}
$$

Then we find

$$
d\left(x_{n}, x_{n+1}\right) \leq d\left(x_{n-1}, x_{n}\right)
$$

for all $n \in \mathbb{N}$. This implies that the sequence $\left\{d\left(x_{n-1}, x_{n}\right)\right\}$ is decreasing and so there is a real number $s \geq 0$ such that

$$
\lim _{n \rightarrow+\infty} d\left(x_{n}, x_{n+1}\right)=s .
$$

Now, we show that $s$ must be equal to 0 . Let $s>0$. Then by taking the limit as $n \rightarrow \infty$ in (46), we get

$$
\psi(s) \leq \psi(s)-\phi(s)
$$

which is a contradiction. Hence we conclude that

$$
\lim _{n \rightarrow+\infty} d\left(x_{n}, x_{n+1}\right)=0
$$

Next, we prove that $\left\{x_{n}\right\}$ is a Cauchy sequence. Suppose, to the contrary, that $\left\{x_{n}\right\}$ is not a Cauchy sequence. Then there exists an $\varepsilon>0$ such that for all positive integer $k$,

$$
\begin{gathered}
n(k)>m(k)>k, \quad d\left(x_{n(k)}, x_{m(k)}\right) \geq \varepsilon, \\
d\left(x_{n(k)}, x_{m(k)-1}\right)<\varepsilon
\end{gathered}
$$

for some sequences $\{m(k)\}$ and $\{n(k)\}$. For all $k \in \mathbb{N}$, we have

$$
\begin{aligned}
\varepsilon \leq & d\left(x_{n(k)}, x_{m(k)}\right) \leq d\left(x_{n(k)}, x_{m(k)-1}\right) \\
& +d\left(x_{m(k)-1}, x_{m(k)}\right) \\
< & \varepsilon+d\left(x_{m(k)-1}, x_{m(k)}\right)
\end{aligned}
$$

Taking the limit as $k \rightarrow+\infty$ in the inequality above and using (50), we get

$$
\lim _{k \rightarrow+\infty} d\left(x_{n(k)}, x_{m(k)}\right)=\varepsilon
$$

Again, from the expressions

$$
\begin{aligned}
d\left(x_{n(k)}, x_{m(k)}\right) \leq & d\left(x_{m(k)}, x_{m(k)+1}\right) \\
& +d\left(x_{m(k)+1}, x_{n(k)+1}\right) \\
& +d\left(x_{n(k)+1}, x_{n(k)}\right), \\
d\left(x_{n(k)+1}, x_{m(k)+1}\right) \leq & d\left(x_{m(k)}, x_{m(k)+1}\right) \\
& +d\left(x_{m(k)}, x_{n(k)}\right) \\
& +d\left(x_{n(k)+1}, x_{n(k)}\right),
\end{aligned}
$$

(50), and (53), we deduce

$$
\lim _{k \rightarrow+\infty} d\left(x_{n(k)+1}, x_{m(k)+1}\right)=\varepsilon
$$

by taking the limit as $k \rightarrow+\infty$. From the facts $\lim _{k \rightarrow+\infty} d\left(x_{m(k)}, x_{m(k)+1}\right)=0$ and $d\left(x_{m(k)}, x_{n(k)}\right) \geq \varepsilon>0$, we deduce that there is $N \in \mathbb{N}$ such that for all $k \geq N$

$$
d\left(x_{m(k)}, x_{m(k)+1}\right) \leq d\left(x_{m(k)}, x_{n(k)}\right) .
$$

Since

$$
\begin{aligned}
& \varphi\left(d\left(x_{m(k)}, x_{m(k)+1}\right)\right) \\
& \quad \leq \frac{1}{2} d\left(x_{m(k)}, x_{m(k)+1}\right) \\
& \quad \leq \frac{1}{2} d\left(x_{m(k)}, x_{n(k)}\right) \leq d\left(x_{m(k)}, x_{n(k)}\right) \\
& \quad \leq \gamma\left(d\left(x_{m(k)}, x_{n(k)}\right)\right)
\end{aligned}
$$

and $x_{m(k)}$ and $x_{n(k)}$ are comparable, by (5), we get

$$
\begin{aligned}
\psi\left(d\left(f x_{m(k)}, f x_{n(k)}\right)\right) \leq & \psi\left(d\left(x_{m(k)}, x_{n(k)}\right)\right) \\
& -\phi\left(d\left(x_{m(k)}, x_{n(k)}\right)\right) .
\end{aligned}
$$

Taking the limit as $k \rightarrow+\infty$ in the inequality above, we have

$$
\psi(\varepsilon) \leq \psi(\varepsilon)-\phi(\varepsilon),
$$

which is a contradiction. Hence $\left\{x_{n}\right\}$ is a Cauchy sequence. Since $X$ is complete, there is a point $z \in X$ such that $x_{n} \rightarrow z$. Furthermore, by condition (iii), $x_{n} \preceq z$. 
Now, we suppose that the following inequalities hold:

$$
\begin{aligned}
\frac{1}{2} d\left(x_{n}, x_{n+1}\right) & \geq \varphi\left(d\left(x_{n}, x_{n+1}\right)\right)>\gamma\left(d\left(x_{n}, z\right)\right) \\
& \geq d\left(x_{n}, z\right), \\
\frac{1}{2} d\left(x_{n+1}, x_{n+2}\right) & \geq \varphi\left(d\left(x_{n+1}, x_{n+2}\right)\right) \\
& >\gamma\left(d\left(x_{n+1}, z\right)\right) \geq d\left(x_{n+1}, z\right)
\end{aligned}
$$

for some $n \in \mathbb{N}$. By (47), we have

$$
\begin{aligned}
d\left(x_{n}, x_{n+1}\right) & \leq d\left(x_{n}, z\right)+d\left(x_{n+1}, z\right) \\
& <\frac{1}{2} d\left(x_{n}, x_{n+1}\right)+\frac{1}{2} d\left(x_{n+1}, x_{n+2}\right) \\
& <\frac{1}{2} d\left(x_{n}, x_{n+1}\right)+\frac{1}{2} d\left(x_{n}, x_{n+1}\right)=d\left(x_{n}, x_{n+1}\right),
\end{aligned}
$$

a contradiction. Thus, for all $n \in \mathbb{N}$, either

$$
\varphi\left(d\left(x_{n}, x_{n+1}\right)\right) \leq \gamma\left(d\left(x_{n}, z\right)\right)
$$

or

$$
\varphi\left(d\left(x_{n+1}, x_{n+2}\right)\right) \leq \gamma\left(d\left(x_{n+1}, z\right)\right)
$$

holds. By (42), it follows that either

$$
\psi\left(d\left(f x_{n}, f z\right)\right) \leq \psi\left(d\left(x_{n}, z\right)\right)-\phi\left(d\left(x_{n}, z\right)\right)
$$

or

$$
\psi\left(d\left(f x_{n+1}, f z\right)\right) \leq \psi\left(d\left(x_{n+1}, z\right)\right)-\phi\left(d\left(x_{n+1}, z\right)\right) .
$$

Consequently, there exists an infinite subset $J \subset \mathbb{N}$ such that one of these inequalities holds for every $n \in J$. If we take the limit as $n \rightarrow+\infty$ and $n \in J$, then we get that $d(z, f z)=0$, that is, $z=f z$ which contradicts with the assumption $z \neq f z$. Hence $z$ is a fixed point of $f$.

Now, assume that condition (iv) holds. To prove the uniqueness of $z$, suppose that $z^{*}$ is another fixed point of $f$. It is easy to see from (5) that $z=z^{*}$, if $z$ and $z^{*}$ are comparable. If $z$ and $z^{*}$ are not comparable, by condition (iv), there exists an $x$ comparable with $z$ and $z^{*}$. Now we suppose that

$$
\begin{aligned}
& \lim _{n \rightarrow+\infty} d\left(f^{n} z, f^{n} x\right)=s_{1}>0, \\
& \lim _{n \rightarrow+\infty} d\left(f^{n} z^{*}, f^{n} x\right)=s_{2}>0 .
\end{aligned}
$$

First we note that for each $x \in X$ comparable with $z$, by (5) with $x=f^{n-1} z$ and $y=f^{n-1} x$, we have

$$
\begin{aligned}
\psi\left(d\left(f^{n} z, f^{n} x\right)\right) \leq & \psi\left(d\left(f^{n-1} z, f^{n-1} x\right)\right) \\
& -\phi\left(d\left(f^{n-1} z, f^{n-1} x\right)\right) .
\end{aligned}
$$

Taking the lim sup as $k \rightarrow+\infty$ in the inequalities above, we have

$$
\psi\left(s_{1}\right) \leq \psi\left(s_{1}\right)-\phi\left(s_{1}\right)
$$

which is a contradiction. Hence $\lim _{n \rightarrow+\infty} d\left(f^{n} z, f^{n} x\right)=0$. Similarly, we obtain that

$$
\lim _{n \rightarrow+\infty} d\left(f^{n} z^{*}, f^{n} x\right)=0
$$

From the inequality

$$
\begin{aligned}
d\left(z, z^{*}\right)= & d\left(f^{n} z, f^{n} z^{*}\right) \leq d\left(f^{n} z, f^{n} x\right) \\
& +d\left(f^{n} x, f^{n} z^{*}\right)
\end{aligned}
$$

we get $d\left(z, z^{*}\right)=0$, that is, $z=z^{*}$, by taking the limit as $n \rightarrow+\infty$.

Example 12. Let $X=\{(0,0),(4,0),(0,4),(4,5),(5,4)\}$. We define a partial order $\sqsubseteq$ by

$$
(x, y) \sqsubseteq(u, v) \Longleftrightarrow x \leq u, \quad v \leq y .
$$

Define the metric $d$ on $X$ by $d\left(\left(x_{1}, x_{2}\right),\left(y_{1}, y_{2}\right)\right)=\mid x_{1}-$ $y_{1}|+| x_{2}-y_{2} \mid$. Clearly, $(X, d)$ is a complete metric space. Also define $f: X \rightarrow X$ by

$$
f\left(x_{1}, x_{2}\right)= \begin{cases}\left(x_{1}, 0\right), & \text { If } x_{1} \leq x_{2} \\ \left(0, x_{2}\right) & \text { If } x_{1}>x_{2}\end{cases}
$$

Let $\varphi(t)=(1 / 2) t, \gamma(t)=t, \psi(t)=t$, and $\phi(t)=(1-r) t$, where $r \in[0,1)$. Hence the conditions of Theorem 11 hold; that is, $f$ has a unique fixed point. But Theorem 2.1 in [36] cannot be applied to $f$ in this example.

Proof. Let $(x, y),(u, v) \in X$, with $(x, y) \sqsubseteq(u, v)$. Then for all elements of $X$ we have

$$
(0,0) \sqsubseteq(4,0), \quad(0,4) \sqsubseteq(5,4), \quad(4,5) \sqsubseteq(5,4) .
$$

We examine each of the following cases:

(i) for $(0,0) \sqsubseteq(4,0)$, we have;

$$
d(f(0,0), f(4,0))=0 \leq \frac{4}{5} d((0,0),(4,0)) ;
$$

(ii) for $(0,4) \sqsubseteq(5,4)$, we have

$$
d(f(0,4), f(5,4))=4 \leq 4=\frac{4}{5} d((0,4),(5,4)) ;
$$

(iii) for $(4,5) \sqsubseteq(5,4)$, we have

$$
d(f(4,5), f(5,4))=8>\frac{8}{5}=\frac{4}{5} d((4,5),(5,4)) .
$$

That is, in [36, Theorem 2.1] cannot be applied to $f$. But for $(4,5) \sqsubseteq(5,4)$,

$$
\frac{1}{2} d((4,5), f(4,5))=\frac{5}{2}>2=d((4,5),(5,4)) .
$$

Hence the conditions of Theorem 11 hold; that is, $f$ has a unique fixed point in $X$. 


\section{Application to Existence of Solutions of Integral Equations}

Let $X=C([0, T], \mathbb{R})$ be the set of real continuous functions defined on $[0, T]$ and $d_{\alpha}: X \times X \rightarrow[0,+\infty)$ be defined by $d(x, y)=\sup _{t \in[0, T]}|x(t)-y(t)|$ for all $x, y \in X$. Let $\preceq$ be the partial order on $X$ defined by $x \preceq y$ if and only if $x(t) \leq y(t)$ for all $t \in[0, T]$. Then $(X, d, \preceq)$ is a complete partially ordered metric space.

Consider the following integral equation:

$$
x(t)=p(t)+\int_{0}^{T} S(t, s) f(s, x(s)) d s,
$$

where

(A) $f:[0, T] \times \mathbb{R} \rightarrow \mathbb{R}$ is continuous,

(B) $p:[0, T] \rightarrow \mathbb{R}$ is continuous,

(C) $S:[0, T] \times[0, T] \rightarrow[0,+\infty)$ is continuous and

$$
\sup _{t \in[0, T]} \int_{0}^{T} S(t, s) d s \leq 1,
$$

(D) there exists a nonempty and closed subset $U \subseteq X$ such that for all $x, y \in U$ with $x \preceq y$, we have

$$
\begin{aligned}
& f(s, y(s))-f(s, x(s)) \\
& \quad \leq \psi(y(s)-x(s)) \quad \forall s \in[0, T],
\end{aligned}
$$

where $\psi \in \Psi$ and for all $x, y \in X$ with $x \preceq y$, we have

$$
0 \leq f(s, y(s))-f(s, x(s))
$$

(E) for all $x \in U$, we have

$$
x(t) \leq p(t)+\int_{0}^{T} S(t, s) f(s, x(s)) d s \in U,
$$

(F) for a strictly increasing sequence $\left\{x_{n}\right\} \subset X$ converging to $x \in X$, we have $x_{n} \prec x$ for all $n \in \mathbb{N}$.

We have the following result of existence of solutions for integral equations.

Theorem 13. Under assumptions $(A)-(E)$, the integral equation (78) has a solution in $X=C([0, T], R)$.

Proof. Let $H: X \rightarrow X$ be defined by

$$
\begin{array}{r}
H x(t)=p(t)+\int_{0}^{T} S(t, s) f(s, x(s)) d s \\
t \in[0, T], \forall x \in X .
\end{array}
$$

First, we will prove that $H$ is a nondecreasing mapping with respect to $\preceq$. Let $x \preceq y$. By (D), we have $0 \leq f(s, y(s))-$ $f(s, x(s))$ for all $s \in[0, T]$. On the other hand by definition of $H$, we have

$$
\begin{array}{r}
H y-H x=\int_{0}^{T} S(t, s)[f(s, y(s))-f(s, x(s))] d s \geq 0 \\
\forall t \in[0, T] .
\end{array}
$$

Then $H x \preceq H y$, that is, $H$ is a non-decreasing mapping with respect to $\preceq$. Now suppose that $x, y \in U$ with $x \preceq y$. Then by (C), (D), and the definition of $H$, we get

$$
\begin{aligned}
d(H x, H y) & =\sup _{t \in[0, T]}|H x(t)-H y(t)| \\
& =\sup _{t \in[0, T]}\left|\int_{0}^{T} S(t, s)[f(s, x(s))-f(s, y(s))] d s\right| \\
\leq & \sup _{t \in[0, T]} \int_{0}^{T} S(t, s)|f(s, x(s))-f(s, y(s))| d s \\
\leq & \sup _{t \in[0, T]} \int_{0}^{T} S(t, s) \psi((y(s)-x(s))) d s \\
\leq & \left(\sup _{t \in[0, T]} \int_{0}^{T} S(t, s) d s\right) \\
& \times \psi\left(\sup _{s \in[0, T]}(y(s)-x(s))\right) \\
\leq & \psi(d(x, y)) .
\end{aligned}
$$

Define $\alpha: X^{2} \rightarrow \mathbb{R}_{+}$by

$$
\alpha(x, y)= \begin{cases}1, & \text { if } x, y \in U \text { with } x \preceq y \\ 0, & \text { otherwise. }\end{cases}
$$

Clearly, $\alpha(x, y) d(H x, H y) \leq \psi(d(x, y))$ holds for all $x, y \in X$ with $x \preceq y$. If $\alpha(x, y) \geq 1$ then $x, y \in U$ and $x \preceq y$. Since, $H$ is increasing, we obtain $H x \preceq H y$. Similarly, since $H x, H y \in U$, we get $\alpha(H x, H y) \geq 1$. Therefore, $H$ is an $\alpha$-admissible mapping. Also, assume that $\left\{x_{n}\right\}$ is a sequence such that $x_{n} \rightarrow x$ as $n \rightarrow \infty$ and $\alpha\left(x_{n}, x\right) \geq 1$. Then $\left\{x_{n}\right\} \subseteq U$. Since $U$ is a closed set, we have $x \in U$. That is, $\alpha\left(x_{n}, x\right) \geq 1$. Then conditions of Theorem 8 hold and $H$ has a solution in $X$.

\section{Acknowledgment}

The first author is supported by Islamic Azad University, Astara Branch.

\section{References}

[1] K. C. Border, Fixed Point Theorems with Applications to Economics and Game Theory, Cambridge University Press, Cambridge, UK, 1985.

[2] E. A. Ok, Real Analysis with Economic Applications, Princeton University Press, Princeton, NJ, USA, 2007.

[3] E. Karapınar, "Generalizations of Caristi Kirk's theorem on partial metric spaces," Fixed Point Theory and Applications, vol. 2011, article 4, 2011.

[4] E. Karapinar, "A note on common fixed point theorems in partial metric spaces," Miskolc Mathematical Notes, vol. 12, no. 2, pp. 185-191, 2011. 
[5] S. G. Matthews, "Partial metric topology", in Papers on General Topology and Applications, vol. 728 of Annals of the New York Academy of Sciences, pp. 183-197, New York Academy of Science, New York, NY, USA, 1994.

[6] S. Romaguera and O. Valero, "A quantitative computational model for complete partial metric spaces via formal balls," Mathematical Structures in Computer Science, vol. 19, no. 3, pp. 541-563, 2009.

[7] M. P. Schellekens, "The correspondence between partial metrics and semivaluations," Theoretical Computer Science, vol. 315, no. 1, pp. 135-149, 2004.

[8] R. Levy, "Fixed point theory and structural optimization," Engineering Optimization, vol. 17, no. 4, 1991.

[9] H. El-Dessouky and S. Bingulac, "A fixed point iterative algorithm for solving equations modeling the multi-stage flash desalination process," Computer Methods in Applied Mechanics and Engineering, vol. 141, no. 1-2, pp. 95-115, 1997.

[10] H. H. Bauschke, R. S. Burachik, P. L. Combettes, V. Elser, D. R. Luke, and H. Wolkowicz, Fixed-Point Algorithms for Inverse Problems in Science and Engineering, vol. 49 of Optimization and Its Applications, Springer, New York, NY, USA, 1st edition, 2011.

[11] S. Banach, "Sur les operations dans les ensembles abstraits et leur application aux equations intégrales," Fundamenta Mathematicae, vol. 3, pp. 133-181, 1922.

[12] R. Kannan, "Some results on fixed points," Bulletin of the Calcutta Mathematical Society, vol. 60, pp. 71-76, 1968.

[13] S. Reich, "Kannan's fixed point theorem," Bollettino della Unione Matematica Italiana, vol. 4, pp. 1-11, 1971.

[14] G. E. Hardy and T. D. Rogers, "A generalization of a fixed point theorem of Reich," Canadian Mathematical Bulletin, vol. 16, pp. 201-206, 1973.

[15] L. B. Ciric, "A generalization of Banach's contraction principle," Proceedings of the American Mathematical Society, vol. 45, pp. 267-273, 1974.

[16] T. Zamfirescu, "Fix point theorems in metric spaces," Archiv der Mathematik, vol. 23, pp. 292-298, 1972.

[17] H. Ni, L.-X. Tian, and X. Liu, "Positive almost periodic solution on a nonlinear differential equation," Mathematical Problems in Engineering, vol. 2011, Article ID 567319, 10 pages, 2011.

[18] Z. Cao, C. Yuan, D. Jiang, and X. Wang, "A note on periodic solutions of second order nonautonomous singular coupled systems," Mathematical Problems in Engineering, vol. 2010, Article ID 458918, 15 pages, 2010.

[19] T. Jitpeera and P. Kumam, "Hybrid algorithms for minimization problems over the solutions of generalized mixed equilibrium and variational inclusion problems," Mathematical Problems in Engineering, vol. 2011, Article ID 648617, 25 pages, 2011.

[20] X. Yang, Y.-C. Liou, and Y. Yao, "Finding minimum norm fixed point of nonexpansive mappings and applications," Mathematical Problems in Engineering, vol. 2011, Article ID 106450, 13 pages, 2011.

[21] L.-L. Huang, L. Xiao, and Z.-H. Wei, "Efficient and effective total variation image super-resolution: a preconditioned operator splitting approach," Mathematical Problems in Engineering, vol. 2011, Article ID 380807, 20 pages, 2011.

[22] M. Edelstein, "On fixed and periodic points under contractive mappings," Journal of the London Mathematical Society, vol. 37, pp. 74-79, 1962.

[23] T. Suzuki, "A generalized Banach contraction principle that characterizes metric completeness," Proceedings of the American Mathematical Society, vol. 136, no. 5, pp. 1861-1869, 2008.
[24] T. Suzuki, "A new type of fixed point theorem in metric spaces," Nonlinear Analysis. Theory, Methods \& Applications, vol. 71, no. 11, pp. 5313-5317, 2009.

[25] I. Altun and A. Erduran, "A Suzuki type fixed-point theorem," International Journal of Mathematics and Mathematical Sciences, vol. 2011, Article ID 736063, 9 pages, 2011.

[26] D. Doric and R. Lazovic, "Some Suzuki type fixed point theorems for generalized multivalued mappings and applications," Fixed Point Theory and Applications, vol. 2011, article 40, 2011.

[27] E. Karapınar, "Remarks on Suzuki (C)-condition," in Dynamical Systems and Methods, pp. 227-243, Springer, New York, NY, USA, 2012.

[28] E. Karapınar and K. Taş, "Generalized (C)-conditions and related fixed point theorems," Computers \& Mathematics with Applications, vol. 61, no. 11, pp. 3370-3380, 2011.

[29] S. L. Singh, H. K. Pathak, and S. N. Mishra, "On a Suzuki type general fixed point theorem with applications," Fixed Point Theory and Applications, vol. 2010, Article ID 234717, 15 pages, 2010.

[30] M. Turinici, "Abstract comparison principles and multivariable Gronwall-Bellman inequalities," Journal of Mathematical Analysis and Applications, vol. 117, no. 1, pp. 100-127, 1986.

[31] A. C. M. Ran and M. C. B. Reurings, "A fixed point theorem in partially ordered sets and some applications to matrix equations," Proceedings of the American Mathematical Society, vol. 132, no. 5, pp. 1435-1443, 2004.

[32] J. J. Nieto and R. Rodríguez-López, "Contractive mapping theorems in partially ordered sets and applications to ordinary differential equations," Order, vol. 22, no. 3, pp. 223-239, 2005.

[33] J. Matkowski, "Integrable solutions of functional equations," Dissertationes Mathematicae, vol. 127, pp. 1-68, 1975.

[34] J. Matkowski, "Fixed point theorems for mappings with a contractive iterate at a point," Proceedings of the American Mathematical Society, vol. 62, no. 2, pp. 344-348, 1977.

[35] B. Samet, C. Vetro, and P. Vetro, "Fixed point theorems for $\alpha$ - $\psi$-contractive type mappings," Nonlinear Analysis. Theory, Methods \& Applications, vol. 75, no. 4, pp. 2154-2165, 2012.

[36] E. Karapınar and P. Salimi, "Fixed point theorems via auxiliary functions," Journal of Applied Mathematics, vol. 2012, Article ID 792174, 9 pages, 2012. 


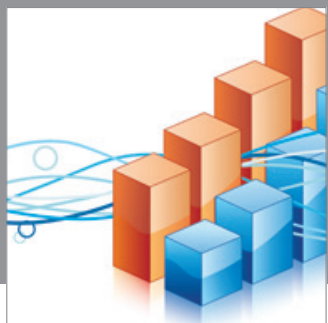

Advances in

Operations Research

mansans

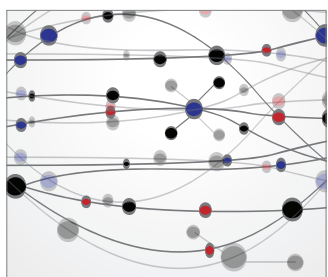

The Scientific World Journal
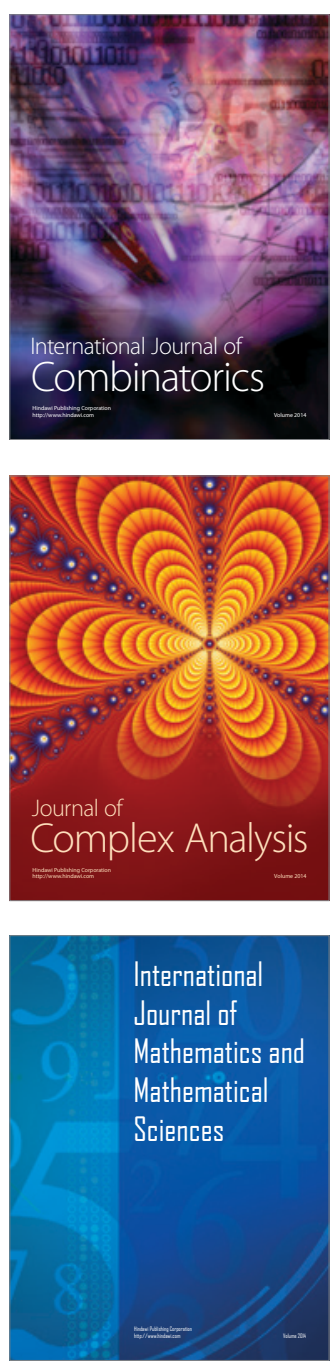
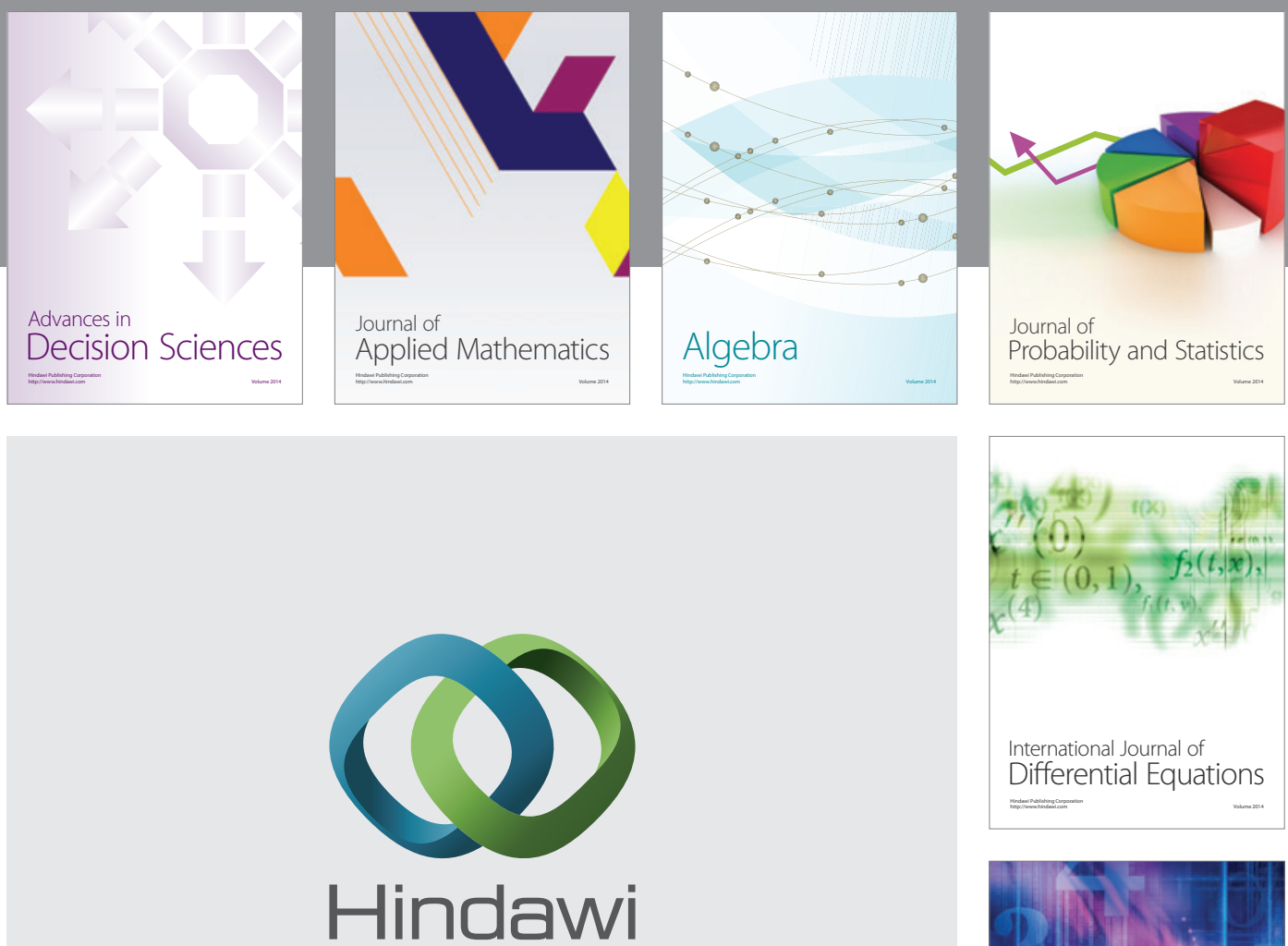

Submit your manuscripts at http://www.hindawi.com
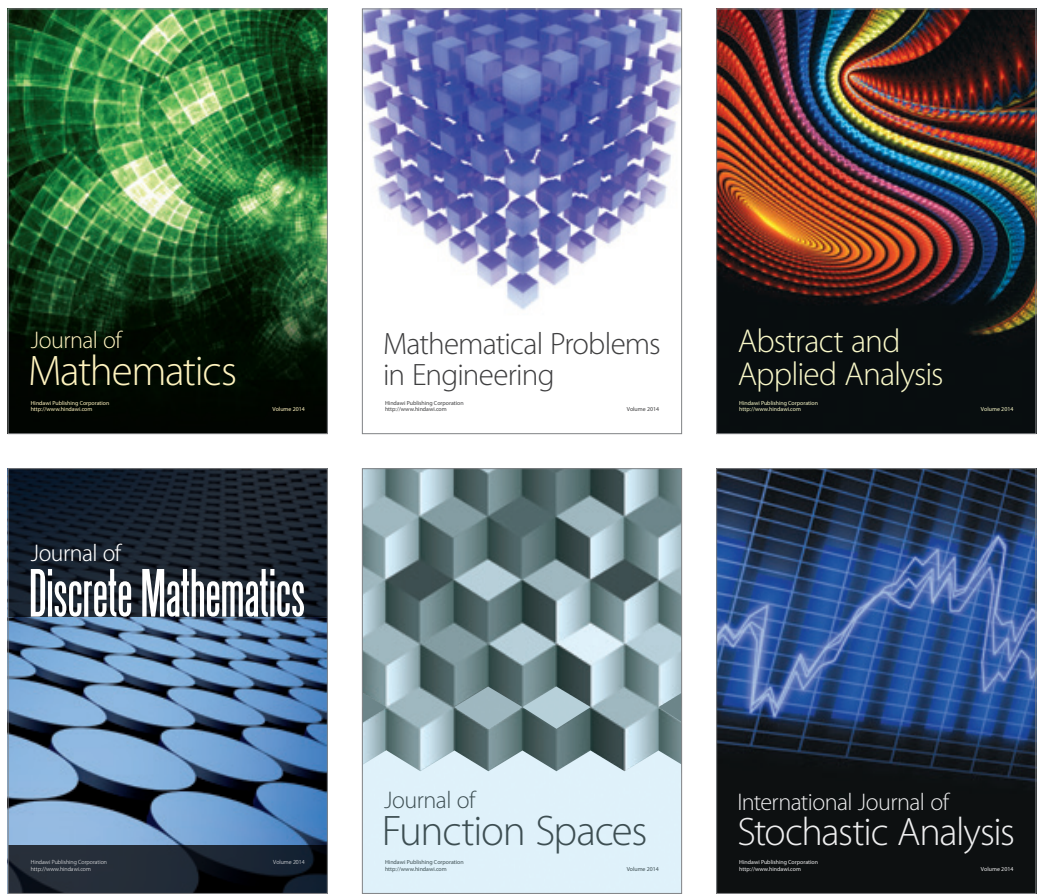

Journal of

Function Spaces

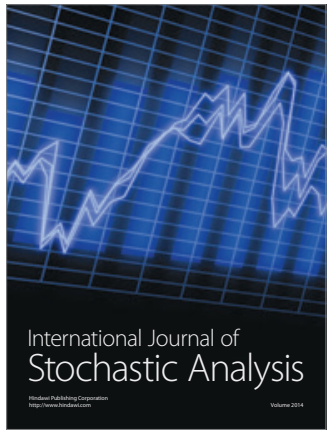

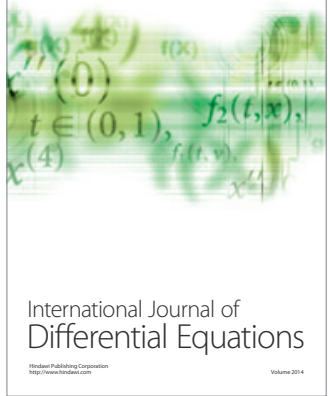
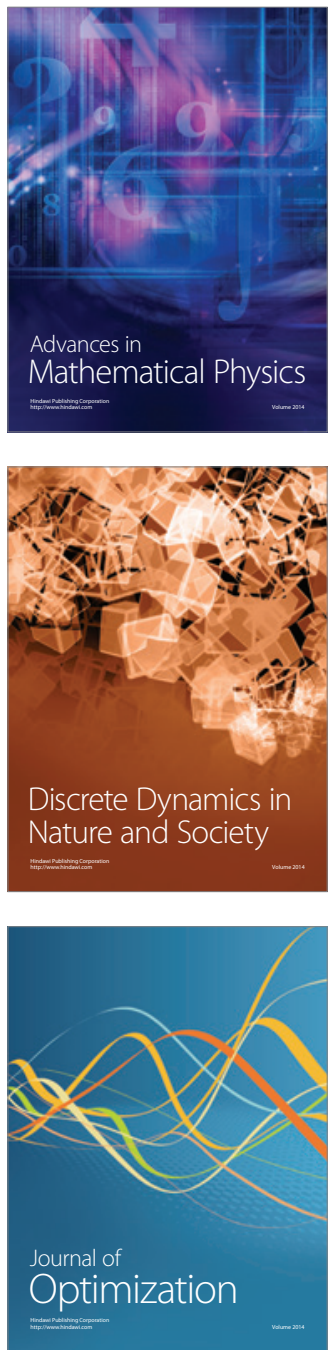